\title{
Surface inversion characteristics in the nocturnal boundary layer of Guadeloupe and its impact on air quality
}

\author{
T. Plocoste, S. Jacoby-Koaly, J. Molinié \& F. Bade \\ Laboratory of Research in Geosciences and Energy (LaRGE), \\ University of Antilles-Guyane, Guadeloupe
}

\begin{abstract}
Dispersion of pollutants in the atmosphere strongly depends on its stability. In nocturnal stable conditions, occurrence of a surface thermal inversion can trap air pollutants near the ground. Such inversion develops after sunset consecutively to radiative cooling of the ground and is dissolved by convection in the morning. In literature, few studies deal with this phenomenon in the tropics. Through measurements carried out in Guadeloupe, we study the inversion depth and intensity from Météo France (MF) soundings at 7 am (11 UTC) in 2011 and 2012. We are also concerned here with its impact on air pollutants concentrations. We detect more cases of surface inversion at the beginning and at the end of the year. Annual global radiation and time of sunrise evolutions are key parameters for understanding its detection on MF soundings at $7 \mathrm{am}$. We find a surface inversion with average height of $121 \mathrm{~m}$ and average intensity of $1.8^{\circ} \mathrm{C}$. When the night inversion is still visible on the early morning temperature sounding, simultaneous pollutants primary measurements always show higher concentrations. At sounding time we get on average, $23.3 \mu \mathrm{g} \cdot \mathrm{m}^{-3}$ of $\mathrm{NO}$ concentration with inversion and $11.8 \mu \mathrm{g} . \mathrm{m}^{-3}$ without.

Keywords: surface inversion, nocturnal boundary layer, soundings, air quality, Guadeloupe.
\end{abstract}

\section{Introduction}

During the day, pollutants dispersion depends on the mixing intensity and the extent of the mixing zone in the lower atmosphere called mixed layer [1]. The height of the mixed layer determines the dispersion height for the emitted 
pollutants from stacks, vehicles or diffuse sources, since a stable inversion layer at the top of the mixed layer prevents the pollutants transfer in the free troposphere. In nocturnal stable conditions, occurrence of a low thermal inversion usually trap air pollutants near the ground. Such inversion is formed at ground level in clear sky conditions [2]. It develops after sunset consecutively to radiative cooling of the ground and is dissolved by convection in the morning [1,3-5]. A surface inversion can be characterized by its depth and its strength [6]. Although many studies have thoroughly investigated the characteristics of thermal inversions during the last years, little work has been done concerning this phenomenon in the tropics [7].

The present study seeks to identify some characteristics of nocturnal inversions in the island of Guadeloupe (Figure 1) at the North of the Lesser Antilles $\left(16^{\circ} 15 \mathrm{~N}\right.$, $\left.61^{\circ} 35 \mathrm{~W}\right)$ and show impact of these inversions occurrence on air pollutants accumulation.

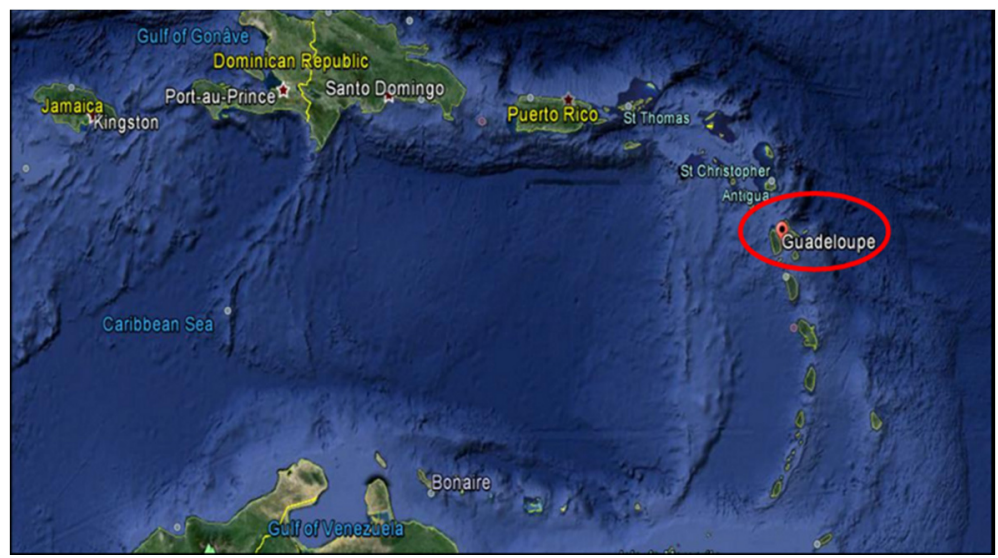

Figure 1: Location of Guadeloupe in the Lesser Antilles, Google earth.

\section{Material and methods}

To carry out this work, we used French Met office, Météo France, radiosonde daily measurements for exhibiting surface inversion characteristics and Guadeloupe air quality network hourly data for establishing pollutant loading.

\subsection{Surface inversions from Météo France radiosonde}

The data were collected from a balloon-borne sensor (radiosonde) of Météo France which is daily launched from the airport meteorological station in the center of the island at 7 am (11 UTC). Measurements of temperature, pressure, wind speed and direction were taken at intervals during flight and allowed us to draw for each day the temperature profiles in 2011 and 2012. Like Yasmeen [2], criteria for identifying the inversion layers is the increase of temperature with height and do not include cases where the temperature remains constant over a vertical layer 
(isothermal layer). In the end, we discuss two situations: profiles without surface inversion ("standard" profiles, Figure 2) and profiles with surface inversion (Figure 3).

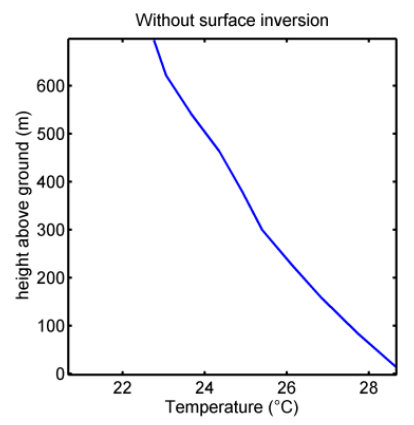

Figure 2: Example of a profile without surface inversion at $7 \mathrm{am}$.

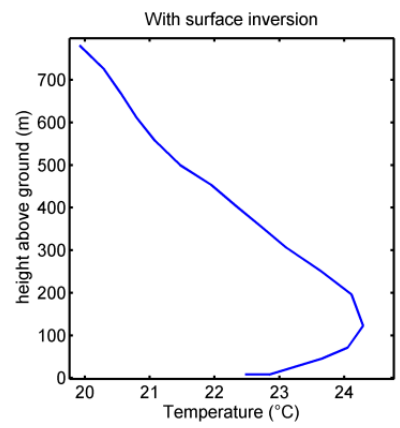

Figure 3: Example of a profile with surface inversion at $7 \mathrm{am}$.

Météo France radiosondes are carried on in the early morning. At this time, Baumbach and Vogt [1] such as Abdul-Wahab et al. [6] showed that the layer inversion is gradually eroded from bottom-up as the heating of the surface. Profile of Figure 2 (without inversion) is representative of diurnal conditions with the occurrence of a more or less strong convection in a layer usually unstable. The nocturnal boundary layer is no more visible on such profiles. Figure 3 exhibits the features of a nocturnal temperature profile that does not undergo any convection and topped by the residual layer due to the mixed layer of the previous day. Between both cases of Figures 2 and 3, some profiles (not discussed here) present intermediate characteristics with a reduced inversion layer trapped between the beginning of the convection at the ground and the residual layer.

In the literature, the strength $(\Delta \mathrm{T})$ and the depth $(\Delta \mathrm{Z})$ of the inversion are calculated by eqn (1) and (2) [6]:

$$
\begin{aligned}
\Delta T\left({ }^{\circ} \mathrm{C}\right) & =T^{\circ}{ }_{i}-T^{\circ}{ }_{b} \\
\Delta Z(m) & =Z_{i}-Z_{b}
\end{aligned}
$$


whereas illustrated on Figure $4 \mathrm{~T}^{\circ}$ is the temperature at the top of the inversion $\mathrm{T}^{\circ}{ }_{\mathrm{b}}$ the temperature at the base of the inversion, $\mathrm{Z}_{\mathrm{i}}$ the height at the top of the inversion, $\mathrm{Z}_{\mathrm{b}}$ the height at the base of the inversion. In what follows these four parameters are determined each time a surface inversion appears on the temperature profile.

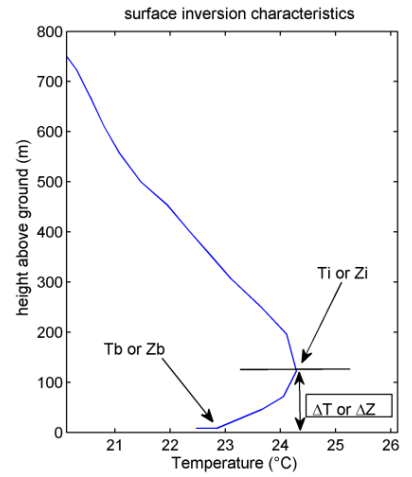

Figure 4: Example of a profile with surface inversion characteristics.

\subsection{Pollution measurements through Guadeloupe air quality network data}

Guadeloupe air quality network is composed of three fixed stations: Abymes, Pointe à Pitre and Baie-Mahault. The distance and position of each station are shown in Table 1 and Figure 5. The reference point is the airport station where the radiosonde is launched.

Table 1: Distance and position of each station compared to MF airport station.

\begin{tabular}{|c|c|c|}
\hline & Distance $(\mathrm{km})$ & Position \\
\hline Abymes & 0.2 & South South West (SSW) \\
\hline Pointe-à-Pitre & 2.35 & South South West (SSW) \\
\hline Baie-Mahault & 6.7 & West (W) \\
\hline
\end{tabular}

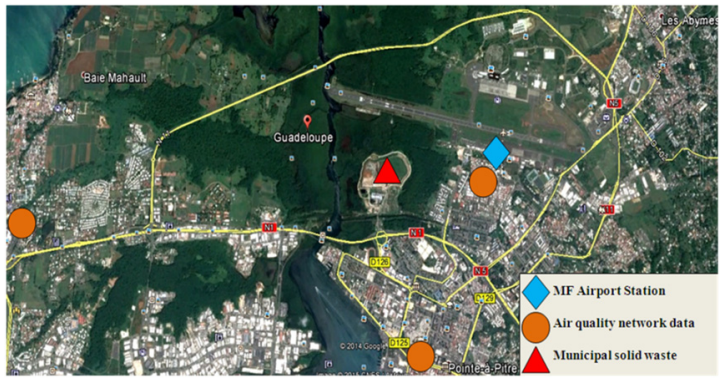

Figure 5: $\quad$ Studied area. This figure shows all the measurements points discussed in our study and the main municipal solid waste of the island (in red), Google earth. 
We focused on air pollutants usually measured in urban area by air quality networks. These pollutants are particles $\left(\mathrm{PM}_{2.5}-\mathrm{PM}_{10}\right)$, nitrogen oxides $\left(\mathrm{NOx}=\mathrm{NO} \& \mathrm{NO}_{2}\right)$ and ozone $\left(\mathrm{O}_{3}\right)$. The concentration of each pollutant is determined by standard methods that are already widely described in the literature. $\mathrm{PM}_{2.5}$ and $\mathrm{PM}_{10}$ are measured by tapered element oscillating microbalance (TEOM) system [8, 9], NOx by chemiluminiscence [10] and $\mathrm{O}_{3}$ by $\mathrm{UV}$ absorption [11]. For all pollutants, measurements are performed continuously. An average of these measurements is calculated at different time intervals before storage in a database. In our study, we will focus on hourly averages in 2011 and 2012 for comparison with meteorological radiosonde data.

\section{Results and discussion}

\subsection{Surface inversion characteristics}

When analyzing the temperature profile as a function of altitude in 2011 and 2012 each day the nocturnal visible layer is detected, we get the following average characteristics (Table 2).

Table 2: Average characteristics of surface inversion in 2011 and 2012.

\begin{tabular}{|c|c|c|c|c|c|c|}
\hline & $\mathrm{Z}_{\mathrm{b}}(\mathrm{m})$ & $\mathrm{Z}_{\mathrm{i}}(\mathrm{m})$ & $\mathrm{T}_{\mathrm{b}}\left({ }^{\circ} \mathrm{C}\right)$ & $\mathrm{T}_{\mathrm{i}}\left({ }^{\circ} \mathrm{C}\right)$ & $\Delta \mathrm{Z}(\mathrm{m})$ & $\Delta \mathrm{T}\left({ }^{\circ} \mathrm{C}\right)$ \\
\hline Surface inversion & 0 & 121 & 22.8 & 24.4 & 121 & 1.8 \\
\hline
\end{tabular}

We find a surface inversion with an average height of $121 \mathrm{~m}$ and an average intensity of $1.8^{\circ} \mathrm{C}$.

As we said earlier, many temperature profiles as on Figure 2 did not include a surface inversion layer. For these morning radiosondes, we could not access the nocturnal boundary layer height. In fact, although climate seasonality is little marked in Guadeloupe compared to other globe areas, the island knows two seasons: a dry and colder season which runs from January to June and a rainy and hotter season that lasts from July to December. Apparition of a surface inversion on the temperature profile at 7 am depends on the time of year as shown in the next section.

\subsection{Surface inversion frequency of occurrence in the morning on Météo France soundings}

The frequency of occurrence of the surface inversion on the radiosonde is shown in Figure 6 for 2011 and 2012.

In Figure 6(a) and 6(b), we observe the same trend in 2011 and 2012. We detect more cases of surface inversion at the beginning (January to March) and the end (November to December) of the year. Between May and July, we note no case of surface inversion. In 2011, we detect less than five cases of surface inversion for April and between August and October. For 2012, we count the same low number of cases of inversion between August and October. 

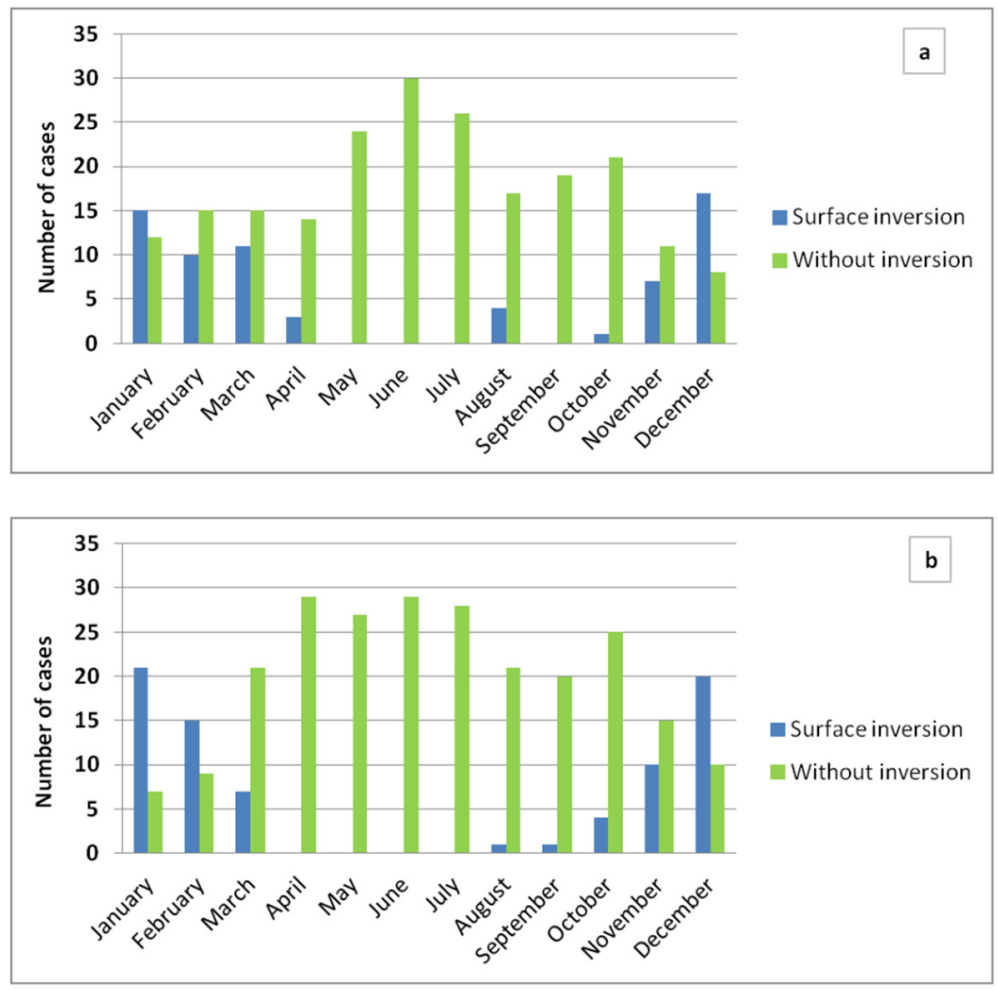

Figure 6: Monthly variation of the number of cases with surface inversions detected or not on Météo France soundings at 7 am in 2011 (a) and 2012 (b).

Knowing that throughout the year Météo France radiosonde are launched at the same hour in the early morning, we tried to determine what criteria could influence the presence or not of an inversion on the temperature profile.

\subsection{Parameters that correlate with the detection of the surface inversion}

\subsubsection{Daily global radiation}

The results of a study by Brévignon [12] on daily global radiation in Guadeloupe between 1991 and 2000 is presented on Figure 7.

We observe that the maximum value of global radiation is reached in the middle of the year $\left(\approx 2200 \mathrm{~J} \mathrm{~cm}^{-1}\right)$ i.e. when the days are the longest. Conversely, it is minimal in December when the days are shorter $\left(\approx 1450 \mathrm{~J} \mathrm{~cm}^{-1}\right)$.

Comparing Figure 6(a) and 6(b) to Figure 7, we conclude that the months with most cases of surface inversion correspond to months with the lowest daily global radiation. We also see that the months with strong daily global radiation correspond to the months with the least number of inversion cases. 


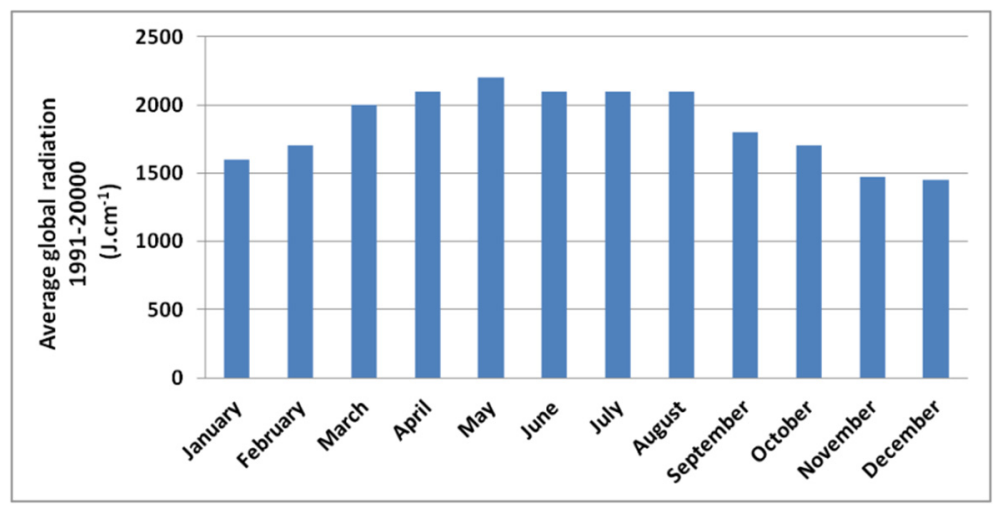

Figure 7: Daily global radiation in Guadeloupe between 1991 and 2000 [12].

We know that convection intensity depends on ground warming. Warming will be conditioned by the amount of heat received by solar radiation already stored in the ground at release time of radiosonde, i.e. of the sunrise hour. We conduct an analysis on the seasonal evolution of the sunrise in the following.

\subsubsection{Sunrise hour}

To get the time of sunrise in 2011 and 2012, we used a software developed by "The Weather Channel" (TWC) [13]. The results are shown on Figure 8.

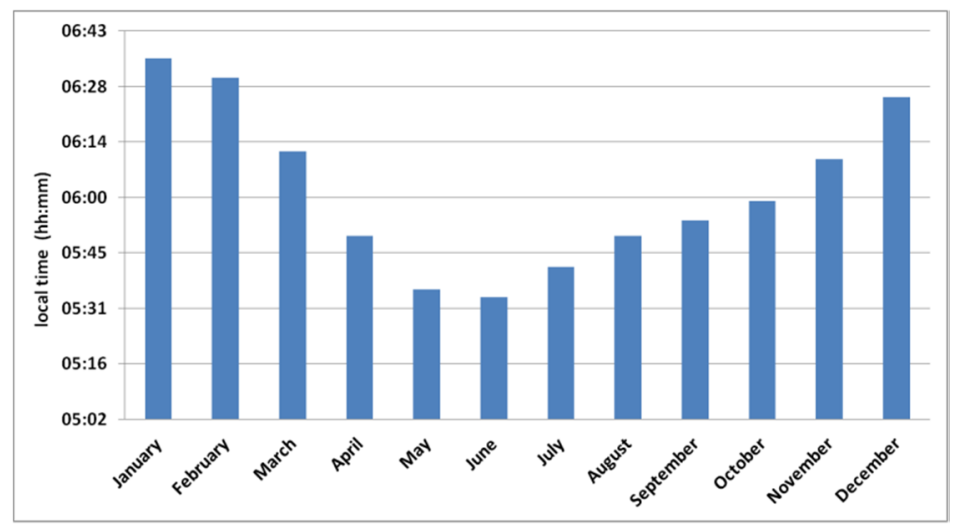

Figure 8: Average sunrise time in Guadeloupe for 2011 and 2012 compute with TWC data.

The results obtained show that the first and last months of the year are associated with later sunrise. Indeed from November to March, the sun rises after $6 \mathrm{am}$. Between April and October, sunrise occurs earlier. On Figure 7 and 8, the months during when the sun rises later correspond to a lower daily global radiation. When the sun rises the earliest, is from May to July (before $5.45 \mathrm{am}$ ). On Figure 6(a) and 6(b), this period is not associated with surface inversion. These 
results emphasize what we said before: the earlier the sun rises, the warmer the ground surface is and the stronger the convection is at the radiosonde time. So the radiosonde temperature profiles of the corresponding months do not exhibit any surface inversion. The detection of the nocturnal boundary layer height is only possible for the days of later sunrise at the beginning and the end of the year.

\subsection{Impact of surface inversion height on atmospheric pollutants concentrations}

Pollutants concentrations measured by the Guadeloupe air quality network are examined at the same time of the Météo France radiosonde. To avoid comparisons bias due to rainfall washout of the atmosphere during our studied period, we have eliminated in our data base every night with rainfall exceeding a total of more than $0.4 \mathrm{~mm}$ between $6 \mathrm{pm}$ and $6 \mathrm{am}$. Then we performed an average on pollutants concentrations between 7 am and 8 am for each day. Finally considering all data of both 2011 and 2012, for each pollutant and for each measurement station, we got two values: with and without surface inversion (Figure 9).

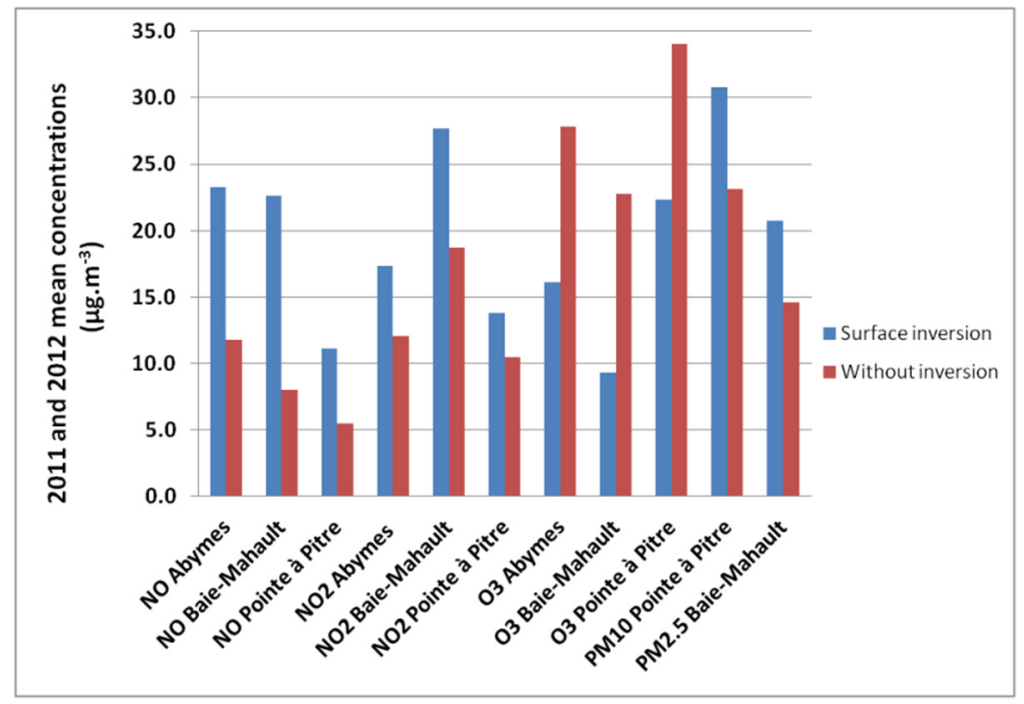

Figure 9: Influence of surface inversion occurrence in temperature profiles on 2011 and 2012 mean concentrations of air pollutants measured by the Guadeloupe air quality network at different locations.

In Figure 9, we see that the presence of the surface inversion increases concentration of $\mathrm{NO}_{\mathrm{x}}$ especially for $\mathrm{NO}$. NO concentrations are at least doubled for each location. At Abymes, with surface inversion, we get a mean value of 23.3 $\mu \mathrm{g} . \mathrm{m}^{-3}$, instead of $11.8 \mu \mathrm{g} . \mathrm{m}^{-3}$ without inversion; for Pointe à Pitre, $11.1 \mu \mathrm{g} . \mathrm{m}^{-3}$ instead of $5.5 \mu \mathrm{g} \cdot \mathrm{m}^{-3}$; and for Baie-Mahault, $22.6 \mu \mathrm{g} \cdot \mathrm{m}^{-3}$ instead of $8 \mu \mathrm{g} . \mathrm{m}^{-3}$. For $\mathrm{NO}_{2}$, this tendency is a little less important, but the difference between both cases is anyway notable. Particulate pollutants $\left(\mathrm{PM}_{10}\right.$ and $\left.\mathrm{PM}_{2.5}\right)$ are also affected by the 
presence of this surface inversion. For $\mathrm{PM}_{10}$, at Pointe à Pitre, we get an average of $30.8 \mu \mathrm{g} . \mathrm{m}^{-3}$ with surface inversion, instead of $23.1 \mu \mathrm{g} . \mathrm{m}^{-3}$ without inversion. For $\mathrm{PM}_{2.5}$, at Baie-Mahault, $20.8 \mu \mathrm{g} \cdot \mathrm{m}^{-3}$ instead of $14.6 \mu \mathrm{g} \cdot \mathrm{m}^{-3}$. When the radiosonde does not include a surface inversion, the nocturnal boundary layer is substituted with a quickly growing diurnal mixed layer with increasing convection leading to a better dilution of primary pollutants.

For $\mathrm{O}_{3}$, we note on Figure 9 an opposite behavior pattern. Whatever place, concentrations for cases without surface inversion are significantly higher. This could be explained by the diurnal cycle of tropospheric ozone. During night and in the early morning, ozone chemistry is dominated by the ozone destruction due to the reaction with NO, which results in lower ozone. When diurnal conditions are established (without surface inversion), we can suppose that a sooner sunrise is followed by a sooner beginning of photochemical ozone production which is then the predominant process in the ozone cycle.

\section{Conclusion}

This study allowed the characterization of the surface inversion associated to the late night nocturnal boundary layer in Guadeloupe (North Atlantic tropical area) between 2011 and 2012. When the night inversion is still visible on the early morning temperature sounding, we find a surface inversion with average height of $121 \mathrm{~m}$ and average intensity of $1.8^{\circ} \mathrm{C}$. We detect more cases of surface inversion at the beginning (January to March) and end (November to December) of the year. Between March and November, the detection of the nocturnal boundary layer is more difficult at 7 am because Météo France radiosonde is no longer representative of night conditions. During this period, nighttime surface inversion characterization would need a sooner radiosonde launch.

On secondary pollutant such as ozone, chemistry processes mainly involved in the pollutants diurnal cycle are not the same at day and at night. So we could not compare ozone evolution between the daytime conditions (no surface inversion) and the nighttime conditions (with surface inversion). On primary pollutants (NOx and particulate pollutants), we note that surface inversion increases the concentration of contaminants within a radius of at least $7 \mathrm{~km}$ around the radiosonde launching area. NO is the most affected by the surface inversion occurrence since its concentration is doubled.

Detected at less than $3 \mathrm{~km}$ from the main municipal solid waste of the island, this surface inversion could potentially enhance VOCs concentrations emitted by the landfill in nearby urban areas [14].

\section{Acknowledgements}

The authors would like to thank Météo France (French Met Office) and GWAD'AIR (Guadeloupe air quality network) for providing data and observations. 


\section{References}

[1] Baumbach, G., \& Vogt, U., Influence of inversion layers on the distribution of air pollutants in urban areas. Water, Air \& Soil Pollution, 3, pp. 65-76, 2003.

[2] Yasmeen, Z., Inversion layer and its environmental impact over Karachi. Pakistan Journal of Meteorology, 7, pp. 53-62, 2011.

[3] Sportisse, B., Pollution atmospherique. Des processus à la modélisation, Springer-Verlag France, pp. 113-120, 2008.

[4] Fritz, B. K., Hoffmann, W. C., Lan, Y., Thomson, S. J., \& Huang, Y., Lowlevel atmospheric temperature inversions and atmospheric stability: characteristics and impacts on agricultural applications. Agricultural Engineering International: the CIGR Ejournal, 10, pp. 1-10, 2008.

[5] Iacobellis, S. F., Norris, J. R., Kanamitsu, M., \& Tyree, M., Climate variability and California low-level temperature inversions. California Climate Change Center, Institution of Oceanography, pp. 1-48, 2009.

[6] Abdul-Wahab, S. A., Bakheit, C. S., \& Siddiqui, R. A., Study the relationship between the health effects and characterization of thermal inversions in the Sulfanate of Oman. Atmospheric Environment, 39, pp. 5466-5471, 2005.

[7] Plocoste, T., Etude de la dispersion nocturne de polluants atmosphériques issus d'une décharge d'ordures ménagères. Mise en évidence d'un îlot de chaleur urbain, Thesis at Université des Antilles et de la Guyane, pp. 164177, 2013.

[8] Cyrys, J., Dietrich, G., Kreyling, W., Tuch, T., \& Heinrich, J., PM2.5 measurements in ambient aerosol: comparison between Harvard impactor (HI) and the tapered element oscillating microbalance (TEOM) system. The Science of the Total Environment, 278, pp. 191-197, 2001.

[9] Charron, A., Harrison, R., Moorcroft, S., \& Booker, J. (2004). Quantitative interpretation of divergence between PM10 and PM2.5 mass measurement by TEOM and gravimetric (Partisol) instruments. Atmospheric Environment, 38, pp. 415-423, 2004.

[10] Godet, Y., \& Triart, B., Evaluation d'un analyseur de NO/NOx par chimiluminescence, INERIS, pp. 10-11, 2003.

[11] Raventos, C., Aujay, R., \& Moquet, A., Evaluation d'un analyseur d'ozone par absorption UV, INERIS, pp. 9-10, 2003.

[12] Brévignon, C., Atlas Climatique. Météo. France Edition, pp. 79-80, 2003.

[13] The Weather Channel, www.weather.com.

[14] Plocoste, T., Jacoby-Koaly, S., Molinié, J., \& Petit, R., Evidence of the effect of an urban heat island on air quality near a landfill. Urban Climate, 10, pp. 745-757, 2014. 